women concerned about contracting an STI, nearly half (49\%) worry about trich increasing their risk of HIV. Only 5\% indicate preterm birth and low birth weight babies as cause for concern. After reading a description of $55 \%$ say they are likely to ask their healthcare provider to test for trich. The facts most likely to make women get tested: testing is simple, easy, and painless and trichomoniasis can be easily cured; trichomoniasis doesn't always show signs or symptoms.

Conclusions Awareness of trichomoniasis is very low. A number of factors affect whether women will choose to be tested. Education about different causes of vaginal discharge, consequences of trich, and ease of testing and treating are important.

\section{P4.116 THE EFFICIENCY OF THE MODEL «PEER DRIVEN INTERVENTION» AMONG THE WOMEN OF COMMERCIAL SEX AND POSITIVE EXPERIENCE OF REALIZATION OF THE PROJECT ON THE HIV PREVENTION BY THE MODEL OF «PDI» IN CRIMEA}

doi:10.1136/sextrans-2013-051184.1013

\section{S R Kucherova. Charitable Foundation, Simferopol, Ukraine}

By the CF «Hope and rescue» in Simferopol in 2010 was realised one of the first projects in the world-the pilot project on the HIV prevention among the women of commercial sex (WCS) with the help of the model «Peer Driven Intervention».

Primary purpose of this intervention was involving of new clients especially from priority difficult of access groups, providing the clients with new and comprehensive knowledge's on the HIV, STD prevention and less risky sexual behaviour.

Introduction of the project on HIV prevention among WCS by a model «PDI» was very urgent for the region because the majority of the WCS are part of the so-called "closed group». It is very difficult to involve these women in participating of the projects on HIV and STD prevention, overcome services of the programme «Harm reduction».

The women of commercial sex, which were not the clients of the project «Harm reduction», were the target group of the project. The priority group included women of commercial sex at the age to 25 years inclusive.

The peculiarity of the model «PDI» consisted in that every participant of the project got the possibility to take part independently in measures on prevention in their own community. In the project women are interviewed, taught and get preventive services. Model «PDI» provides a motivational gift for every client for passing of the interview, nominal money fee for involving of WCS from a priority group and gifts for the successful teaching of WCS from their community.

With the help of the project we managed to involve 544 clients which later became the clients of the project "Harm reduction". Together with active participating of WCS in the preventive programmes the very important result of the project revealed in a changing of the behaviour for less risky.

\section{P4.117 BRAZILIAN STRATEGIES FOR ADHERENCE TO USE OF FEMALE CONDOMS}

doi:10.1136/sextrans-2013-051184.1014

E Pasini, J Kraiczyc, S S S Barbosa, E Z Ayer. Department of STDS, AIDS and Viral Hepatitis, Brasilia, Brazil

Background HIV prevention success requires a number of sustainable, specific and inter-sectorial actions, among which is expanded access to inputs such as female condoms. Female condoms expand the strategies to fight the feminization of AIDS and unplanned pregnancies. Brazil has increased the purchase of these condoms from 2 million per year to 50 million units per year. Considering the importance of adapting strategies regarding female condom use to Brazilian reality, a qualification and awareness-raising process for the use and distribution of female condoms to users and professionals was developed in 2012 with the purpose of reducing gender inequalities and ensuring sexual and reproductive rights.

Methods Pilot workshops were conducted in three Brazilian state capitals (Porto Alegre, RS; São Paulo, SP; Brasília, DF) using focal group methodology and participant observation. The groups consisted of: managers and professionals from government programmes, young and adult female users of basic healthcare units, young and adult women living with HIV/AIDS, sex workers, and injectable drug users. This study attempted to obtain information for the formulation of a communication strategy for promoting and increasing accessibility to and usage of female condoms, while concurrently training participants in the implementation of strategic actions based on their own experiences.

Results Some of the strategic issues concerning female condom adherence pointed out by the groups were: knowledge of the input's effectiveness, the need for men's participation, erotization strategies, and use by older women (who also aided in the development and promotion of information materials).

Conclusion The groups organised were essential for improving female condom access and usage strategies and in promoting women's human rights, especially with regard to the exercise of their own sexuality.

\section{P4.118 HIV NONDISCLOSURE: A RIGHT TO KNOW?}

doi:10.1136/sextrans-2013-051184.1015

K S Buchanan. University of Southern California Law, Los Angeles, CA, United States

In many jurisdictions, it is a crime for an HIV-positive person to have sex without first disclosing his or her serostatus. Such prosecutions persist in spite of substantial evidence that they do not reduce transmission or risky behaviour. I argue that an underexamined sexual autonomy rationale undergirds such prosecutions. U.S. and Canadian courts have held that nondisclosure of HIV violates a partner's right to "informed" sexual consent, transforming otherwise consensual sex into a crime akin to rape. The sexual autonomy rationale draws on feminist insights about sexual coercion and consent, but has not yet been subjected to rigorous feminist critique. This Article presents the first-ever comprehensive analysis of identifiable nondisclosure prosecutions in the United States, and advances a critical race feminist challenge to the premises and application of this rationale. Criminal law does not protect a general rule that sexual consent be "informed": while HIV nondisclosure is a crime, almost all other forms of sexual deception_often presumed to be normative lies men tell to women are lawful. HIV disclosure laws are also so under- and overinclusive with respect to transmission risk that they seem better designed to reduce anxiety about HIV than to reduce transmission. Furthermore, criminal protection of this interest is selective. Although most sexual transmission of HIV_and, likely, most nondisclosure takes place between men, most defendants are men accused of nondisclosure to women. Racialized and sexual HIV stigma intersects with gendered assumptions about sexual victimisation so that, when a woman has noncommercial heterosex without knowing that her partner had HIV, she, unlike other uninformed sexual partners, may be seen as a victim of sexual crime.

\section{P4.119 STATE CHARACTERISTICS ASSOCIATED WITH THE PRESENCE OF LAWS AUTHORIZING EXPEDITED PARTNER THERAPY IN THE UNITED STATES}

doi:10.1136/sextrans-2013-051184.1016

R Cramer, L T Haderxhanaj, H W Chesson, J S Leichliter. US Centers for Disease Control and Prevention, Atlanta, GA, United States 
Background To examine the associations between social characteristics of US states and the presence of laws authorising expedited partner therapy (EPT).

Methods Data were collected from various sources for 2008-2010 on US state healthcare system characteristics (adult enrollment in Medicaid, number of physicians per 100,000), governmental characteristics (the size of state legislatures, percent of state residents in poverty, percent state financial contribution to state STD programme), and state STD morbidity (chlamydia rates per 100,000 among females age 15-24). Data were analysed in an adjusted logistic regression model in SAS.

Results Overall, 23 states have passed legislation authorising EPT as of February 2013. In adjusted analyses, the only healthcare system variable significantly associated with the presence of a state law authorising EPT was higher adult Medicaid enrollment (AOR $=7.871$ [95\% CI: 1.644, 37.685]), which may represent an increased willingness to authorise EPT where publicly-funded healthcare coverage is more widely available. The only other variable significantly associated with the presence of a law authorising EPT was lower chlamydia rates per 100,000 among females age 15-24 (AOR $=0.332$ [95\% CI: 0.122, 0.903]). The presence of a state law authorising EPT did not differ by the size of the state legislature, percent in poverty, percent state contribution to state STD programme, or number of physicians per 100,000.

Conclusions States with higher adult Medicaid enrollment and lower chlamydia rates among females 15-24 were more likely to have a law authorising EPT. Increased adult Medicaid enrollment may represent an increased willingness of a state to provide publicly-funded healthcare services to its residents; the legal acceptability of EPT may thus be associated with general willingness to provide publicly-funded healthcare within a jurisdiction. This may translate to increased social compatibility of laws authorising EPT in non-US jurisdictions characterised by high rates of publiclyfunded healthcare.

\section{P4.120 EVALUATING THE IMPACT OF SHORT TERM FINANCIAL INCENTIVES ON HIV AND STI INCIDENCE AMONG YOUTH IN LESOTHO: A RANDOMISED TRIAL}

doi:10.1136/sextrans-2013-051184.1017

'M Björkman-Nyqvist, ${ }^{2} \mathrm{~L}$ Corno, ${ }^{3} \mathbf{D}$ de Walque, ${ }^{4} \mathrm{~J}$ Svensson. ${ }^{1}$ Stockholm School of Economics, Stockholm, Sweden; 2 University College London, London, UK; ${ }^{3} T$ he World Bank, Washington, DC, United States; ${ }^{4}$ Stockholm University, Institute for International Economic Studies (IIES), Stockholm, Sweden

Background This study tests the hypothesis that a system of rapid feedback and positive reinforcement using a lottery scheme as an incentive to reduce risky sexual behaviour can be used to promote safer sexual activity and reduce HIV incidence among youth in Lesotho.

Methods An unblinded, individually randomised control trial with 3426 participants, males and females 18-30 years old drawn from 30 villages in Lesotho. The intervention linked the receipt of lottery tickets to negative results for rapid tests for curable STIs: syphilis and Trichomonas vaginalis. The study objective was to test the efficacy of the lottery incentive scheme in reducing HIV incidence. Participants were randomly assigned to either a control arm $(n=1347)$ or one of two intervention arms eligible to receive lottery tickets: high $(n=1116)$ or low $(n=963)$ value lottery $(1,000$ or 500 South African Rands). All arms received STI testing, counselling, and STI treatment every four months during two years. All participants were tested for HIV at baseline and after 16, 20 and 24 months. Village level lotteries were organised every 4 months in which STI negative individuals from the intervention arms were eligible to participate and during which 4 lottery winners (2 males, 2 females) were drawn. The primary study outcome is HIV incidence.
Results After 2 years of intervention, HIV incidence was significantly lower among study participants eligible for the lotteries (OR $0.75,95 \%$ CI $0.58-0.97$ ), especially among women (OR $0.67,95 \%$ CI $0.52-0.86)$, and in the group eligible for the high prize lotteries (1000 Rands)(OR 0.69, 95\% CI $0.50-0.98)$. No harm reported.

Conclusion The results indicate that short-term financial incentives to engage in safe sex can lead to a measurable decline in HIV incidence. It would however be advisable to replicate such an intervention in other settings.

\section{P4.121 GOVERNMENT ROLE'S IN SUPPORTING KEY POPULATION NETWORK}

doi:10.1136/sextrans-2013-051184.1018

\section{S Warsono. National AIDS Commission, Jakarta, Indonesia}

In the AIDS response, the involvement of key populations is important. It means that without their contribution in AIDS response, it is impossible to prevent new infection.

To that end, the Indonesian National AIDS Commission supports key population groups to form a national network. With the support of the National AIDS Commission, some network such as Indonesian Drug Users Network, Positive Women Network, LSL Network and Sex Worker Network are formed.

To strengthen the network, the National AIDS Commission provides financial and technical support through Indonesia Partnership Fund since 2009. The financial support was allocated for operational cost and offices. Apart form Indonesia Partnership Fund support, Those networks are also supported Global Fund throuhg National AIDS Commission.

In coordination meetings that conducted every three months with all members of the National AIDS Commission, these networks are also invited as observers and provide important input related to the AIDS response. The coordination meeting led by Minister of Public Welfare in January 2010 have decided that these networks should be a part of the member of the National AIDS Commission. Since then, the network has been facilitated with grants and state funds. The funding provides each network some grants for coordination meeting, leadership training, community mobilisation training and other activities.

With such support, Indonesian government has shown some recognition of the role of networks of key populations in the AIDS response which has enabled the network to collaborate with various government agencies such as with the Ministry of Health and Social Ministry. The support of the other Ministries are also emerging following the recognition of these two Ministries. With a variety of existing support, the network has also been able to strengthen the system within each network to take more active role in the AIDS response.

\section{P4.122 EFFECTIVENESS OF COMMUNIDADES POSITIVAS: A RANDOMISED COMMUNITY-LEVEL COMBINATION HIV PREVENTION INTERVENTION FOR MEN WHO HAVE SEX WITH MEN IN PERU}

doi:10.1136/sextrans-2013-051184.1019

'A Silva-Santisteban, ${ }^{2}$ K A Konda, 'S Leon, ${ }^{1} X$ Salazar, ${ }^{1} C$ Sandoval, ${ }^{2} \mathrm{~J}$ Clark, ${ }^{3} \mathrm{~J} D$ Klausner, ${ }^{3} \mathrm{~T} \mathrm{~J}$ Coates, 'C F Caceres. 'Universidad Peruana Cayetano Heredia, Lima, Peru; '2UCLA Program in Global Health, Lima, Peru; ${ }^{3}$ University of California, Los Angeles, Los Angeles, CA, United States

Introduction Comunidades Positivas was a randomised clinical trial that assessed a community-level structural combination HIV prevention intervention for men who have sex with men (MSM) in Peru from 2008-2011. We used a $2 \times 2$ factorial design to determine the independent and combined effectiveness of community-level behavioural and biomedical HIV/STI prevention interventions. 